\title{
Glucose tolerance and insulin secretion in children of mothers with pregestational IDDM or gestational diabetes
}

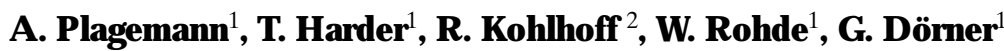 \\ ${ }^{1}$ Institute of Experimental Endocrinology, Humboldt University Medical School (Charité), Berlin, Germany \\ ${ }^{2}$ Clinic of Obstetrics and Gynaecology, Berlin-Kaulsdorf, Germany
}

Summary The offspring of mothers with diabetes mellitus during pregnancy are presumed to develop altered glucose homeostasis. We analysed metabolic parameters at birth and glucose tolerance and insulin secretion during oral glucose tolerance tests at 19 years of age in 129 children born to mothers with pregestational insulin-dependent diabetes (IDDM) and 69 infants of gestational diabetic mothers. Newborns of IDDM mothers displayed higher insulin $(p<0.001)$, glucose $(p<0.05)$, and insulin/glucose ratios $(p<0.002)$ than newborns of gestational diabetic mothers. During childhood, frequencies of impaired glucose tolerance (IGT) rose in infants of IDDM mothers from $9.4 \%$ at $1-4$ years to $17.4 \%$ at 5 9 years of age, while in children of gestational diabetic mothers an increase from $11.1 \%$ up to $20.0 \%$ was observed. Offspring of gestational diabetic mothers displayed higher stimulated blood glucose $(p<0.025)$ than infants of IDDM mothers, while children of IDDM mothers showed higher stimulated insulin $(p<0.025)$, accompanied by increased fasting and stimulated insulin/glucose ratios $(p<0.05$ and $p<0.02$, respectively). Stimulated insulin in childhood was positively correlated to insulin at birth $(p<0.05)$. Furthermore, insulin/glucose ratio in childhood showed a positive correlation to insulin $(p<0.01)$ and insulin/glucose ratio at birth $(p<0.005)$. In conclusion, a pathogenetic role of fetal and neonatal hyperinsulinism for the development of IGT in both groups of infants of diabetic mothers is suggested, in particular for early induction of insulin resistance in the offspring of mothers with pregestational IDDM. [Diabetologia (1997) 40: 1097-1100]

Keywords Children of diabetic mothers, neonatal hyperinsulinism, impaired glucose tolerance, insulin response, insulin resistance.
Since Pedersen's fundamental work [1] the metabolic situation in infants of mothers with diabetes mellitus during pregnancy has been investigated in a number of studies [2-4]. While most authors focussed on

Received: 24 February 1997 and in revised form: 7 May 1997

Corresponding author: Dr. A. Plagemann, Institute of Experimental Endocrinology, Humboldt University Medical School (Charité), Schumannstrasse 20/21, D-10098 Berlin, Germany A bbreviations: AUCG, Area under the curve of glucose; AUCI, area under the curve of insulin; BG0', fasting blood glucose; IDM, infants of pregestational insulin-dependent diabetic mothers; IDDM, insulin-dependent diabetes mellitus; IGDM, infants of gestational diabetic mothers; IGT, impaired glucose tolerance; I0', fasting plasma insulin; NIDDM, non-insulin-dependent diabetes mellitus; OGTT, oral glucose tolerance test. altered glucose homeostasis during neonatal life, it remains unclear if these alterations do persist or resolve in later life. Clinical investigations during childhood indicated elevated frequencies of impaired glucose tolerance (IGT) in the offspring of mothers with diabetes during pregnancy $[5,6]$. Some authors reported alterations of insulin secretion such as hyperinsulinaemia $[6,7]$ which is known to play a key role in the development of metabolic and cardiovascular disturbances in adulthood [8]. Experimental studies in rats displayed long-term alterations of glucose tolerance and insulin secretion due to the induction of maternal gestational hyperglycaemia which leads to fetal and neonatal hyperinsulinism [9-13].

However, only a very small number of studies are available which compared glucose metabolism and 
insulin secretion in infants of mothers suffering from pregestational insulin-dependent diabetes mellitus (IDDM) with those born to mothers with gestational diabetes [14]. Therefore, the aim of this study was to compare features of glucose metabolism and insulin secretion in these children and with regard to the initial situation at birth.

\section{Subjects and methods}

For comparative analysis, data were evaluated in 198 infants of mothers with diabetes during pregnancy. All children (114 males, 84 females) were born between 1980 and 1990 at the Clinic of Obstetrics and Gynaecology in Berlin-Kaulsdorf and were also clinically investigated there. As a centre of the local community health service, the Clinic at Kaulsdorf was attended by around 1800 white Caucasian pregnant women per year for delivery. They represented a population from both urban and rural parts in the southeast of Berlin. During the whole observation period, a total of 741 children (395 males, 346 females) were born to mothers with either pregestational IDDM $(n=368)$ or gestational diabetes $(n=373)$ at the clinic. To all of these mothers, regular examinations of their offspring during childhood were offered, including oral glucose tolerance tests (OGTT). All children who underwent these examinations were included into the study $(n=198)$. Mothers with pregestational IDDM delivered 129 infants (infants of diabetic mothers, IDM). Mean duration of maternal diabetes before pregnancy was $9.2 \pm 5.5$ years. Mothers with gestational diabetes gave birth to 69 infants (infants of gestational diabetic mothers, IGDM). Gestational diabetes was diagnosed between the week 26 and 28 of gestation by means of a $50-\mathrm{g}$ OGTT using the following criteria (two or more abnormal values): fasting venous blood glucose over $5.55 \mathrm{mmol} / \mathrm{l}$, 1 -h value over $8.88 \mathrm{mmol} / \mathrm{l}, 2$-h value over $7.22 \mathrm{mmol} / \mathrm{l}$ [15]. During pregnancy glucose homeostasis was controlled monthly by $24-\mathrm{h}$ glucose monitoring. According to Fuhrmann [15] a mean blood glucose less than $5.55 \mathrm{mmol} / \mathrm{l}$ during 24-h monitoring was taken to indicate adequate glycaemic control in pregnancy. With regard to this criterion, 45 gestational diabetic women were treated with insulin and diet, 24 were treated with diet alone. The mean maternal age at delivery was $26.1 \pm 5.5$ years. Prevalence of paternal diabetes was $3.0 \%$ (6/198; only IDDM occurred). Informed parental consent was given in all cases.

Neonatal measurements. Only term infants were included into the study (week 37-41 of gestation). Birth weight and length were measured in all newborns. Of the neonates $65.1 \%(129$ out of 198) were appropriate for gestational age, $28.3 \%$ (56/ $198)$ were large for gestational age, and $6.6 \%$ (13/198) were found to be small for their gestational age [16]. Data on immunoreactive plasma insulin and blood glucose, determined immediately after delivery in peripheral capillary blood, were available in 87 newborns.
M easurements in infancy. OGTTs with parallel estimations of insulin levels were performed at 1-9 years of age. After an overnight fast, capillary whole blood was obtained for determination of basal glucose (BG0') and insulin levels ( $\mathrm{I}^{\prime}$ ), followed by an oral glucose load with $1.75 \mathrm{~g}$ per kg of body weight. Further blood specimens were taken at 60 and $120 \mathrm{~min}$. IGT was defined according to criteria of the National Diabetes Data Group, particularly recommended for children [17]: fasting glucose in capillary whole blood less than $6.7 \mathrm{mmol} / \mathrm{l}$ and $120-$ min glucose concentration over $6.7 \mathrm{mmol} / \mathrm{l}$. The area under the curve of glucose (AUCG) and the area under the curve of insulin (AUCI) were calculated for detailed analysis of the OGTT. To analyse younger and older children, separately, subjects were divided into age groups 1-4 years old (160 children) and 5-9 years old (38 children).

$\mathrm{L}$ aboratory investigations. Blood glucose was measured automatically [18]. A double antibody radioimmunoassay was performed for the determination of plasma insulin (Serono, Freiburg, FRG; standard: 1.IRP 66/304). Intraassay variation coefficient was $4.5-8.2 \%$ and interassay variation coefficient was $5.6-10.5 \%$, both throughout the duration of the study. Crossreactivity with proinsulin was $15 \%$, those with C-peptide was less than $0.01 \%$.

Statistical analysis. Data are expressed as means \pm SEM. Because of significant non-normality of distribution, glucose and insulin values were log-transformed. Using the log-transformed data, differences between two groups were evaluated by analysis of covariance, adjusted for sex and age. Insulin was additionally tested for group differences after adjusting for glucose concentration by regression. Chi-square test was used to compare frequencies in different groups. To examine the relation between variables, a multiple linear regression analysis was performed. All statistical comparisons are twotailed with $p$ less than 0.05 considered significant. Evaluations were accomplished using the SPSS PC + package (Microsoft).

\section{Results}

Neonatal period. Table 1 shows the data obtained during the neonatal period. No significant differences in birth weigth and length were observed between IDM and IGDM. IDM displayed significantly higher insulin levels than IGDM and significantly higher blood glucose. Furthermore, IDM had a significantly elevated fasting insulin/glucose ratio as compared to IGDM.

Childhood. During the whole observation period of $1-9$ years of age IGT appeared in $10.8 \%$ of IDM $(14 / 129)$ and $13.0 \%$ of IGDM (9/69). IGT was

Table 1. Neonatal parameters in infants of gestational diabetic mothers (IGDM) as compared to infants of pregestational insulindependent diabetic mothers (IDM)

\begin{tabular}{|c|c|c|c|c|}
\hline & IGDM & (n) & IDM & (n) \\
\hline Birth weight (g) & $3460.1 \pm 50.7$ & (69) & $3411.2 \pm 56.8$ & $(129)$ \\
\hline Birth length $(\mathrm{cm})$ & $51.3 \pm 0.23$ & (69) & $51.0 \pm 0.23$ & (129) \\
\hline Plasma insulin $(\mathrm{pmol} / \mathrm{l})^{\mathrm{a}}$ & $229.6 \pm 35.9$ & (27) & $543.2 \pm 48.9$ & $(60)$ \\
\hline Ratio (insulin/glucose) ${ }^{c}$ & $83.3 \pm 17.1$ & (27) & $149.8 \pm 15.2$ & (60) \\
\hline
\end{tabular}

Values are expressed as means \pm SEM. IGDM vs IDM: ${ }^{a} p<0.001 ;{ }^{b} p<0.05 ;{ }^{c} p<0.002$ (analysis of covariance, adjusted for sex) 
Table 2. Prevalence of impaired glucose tolerance (IGT) in 1-4 and 5-9-year-old infants of mothers with gestational diabetes (IGDM) as compared to those of mothers with pregestational insulin-dependent diabetes (IDM)

\begin{tabular}{lllrl}
\hline & IGDM & $(\mathrm{n})$ & IDM & $(\mathrm{n})$ \\
\hline 1-4 years of age & $11.1 \%$ & $(6 / 54)$ & $9.4 \%$ & $(10 / 106)$ \\
5-9 years of age & $20.0 \%$ & $(3 / 15)$ & $17.4 \%$ & $(4 / 23)$ \\
\hline
\end{tabular}

observed in similar frequencies in male (12/ $114=10.5 \%)$ and female children $(11 / 84=13.1 \%$; chi-square-test NS). Comparing early and later childhood (1-4 years vs 5-9 years), frequency of IGT displayed an increase in both groups of children. No significant differences between IGDM and IDM occurred, either at 1-4 years or at 5-9 years of age

Fig. 1A , B. Means ( \pm SEM) of blood glucose and plasma insulin concentrations during oral glucose tolerance tests at (A) 1 4 years of age and $(\mathbf{B}) 5-9$ years of age. IGDM ( $\bigcirc-\bigcirc)$ vs IDM (O): * $\mathrm{p}<0.05$; ** $\mathrm{p}<0.02$; *** $\mathrm{p}<0.005$; **** $\mathrm{p}<0.001$ (analysis of covariance, adjusted for age and sex)
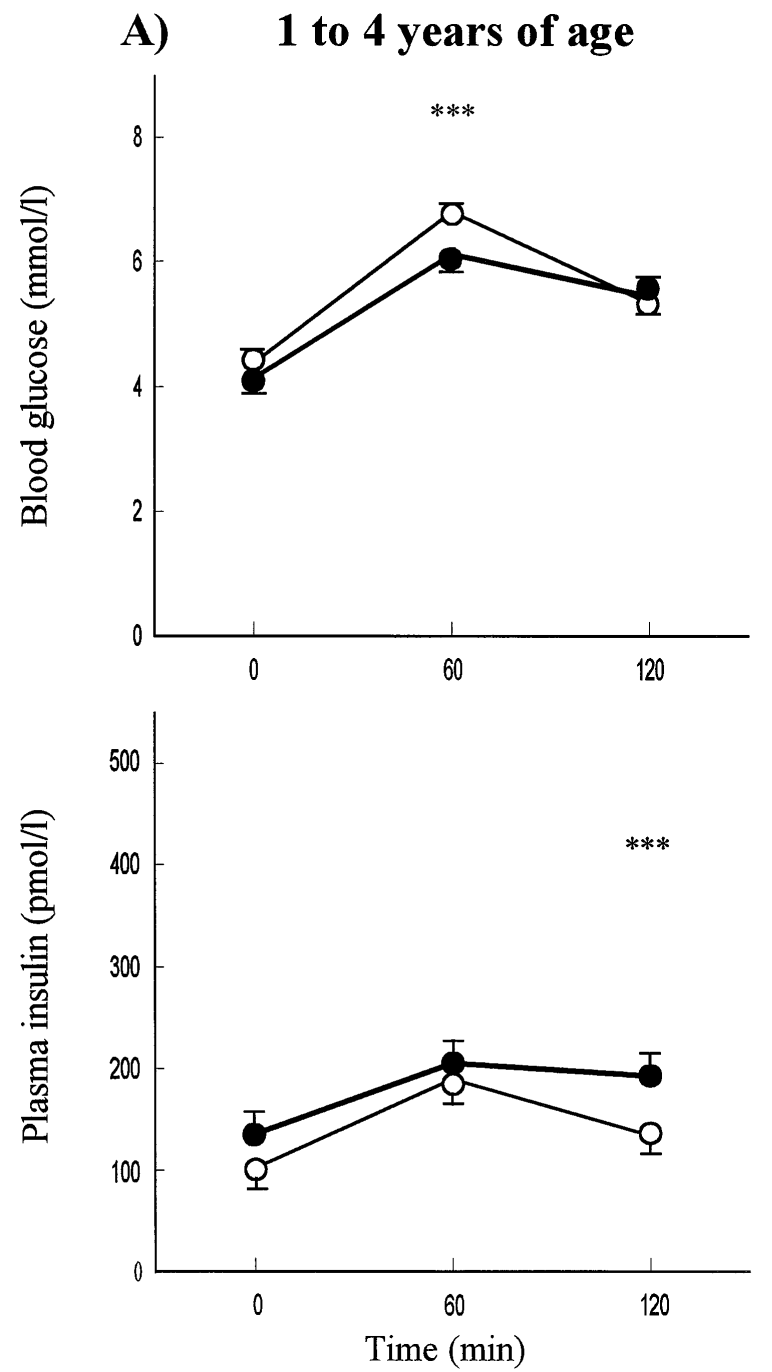

(Table 2). Moreover, if the children of both study groups were divided further, e.g. into three age groups, a continuous increase of IGT frequency with increasing age could be observed (1-3 years: 14/ $144=9.7 \% ; 4-6$ years: $6 / 38=15.8 \% ; 7-9$ years: $3 / 16$ $=18.7 \%$ ).

In order to obtain further details on glucose homeostasis and insulin secretion, the course of glucose and insulin during OGTT was analysed. Figure 1 shows the concentrations of glucose and insulin after a glucose load at 1-4 and 5-9 years of age. Glucose values at $60 \mathrm{~min}$ were found to be significantly higher in IGDM compared to IDM throughout childhood. IDM displayed significantly elevated fasting and 1-h insulin concentrations at 5-9 years of age, while insulin at $120 \mathrm{~min}$ was higher at both ages in IDM, as compared to IGDM. Longitudinal analysis (1-4 vs 5-9 years of age) revealed a significant increase of fasting blood glucose with rising age in both groups of infants of diabetic mothers (IGDM: $p<0.05$; IDM: $p<0.005)$. In IDM, increase of fasting as well as 120 -min glucose values $(p<0.01)$ was accompanied by rising insulin concentrations at 60 and
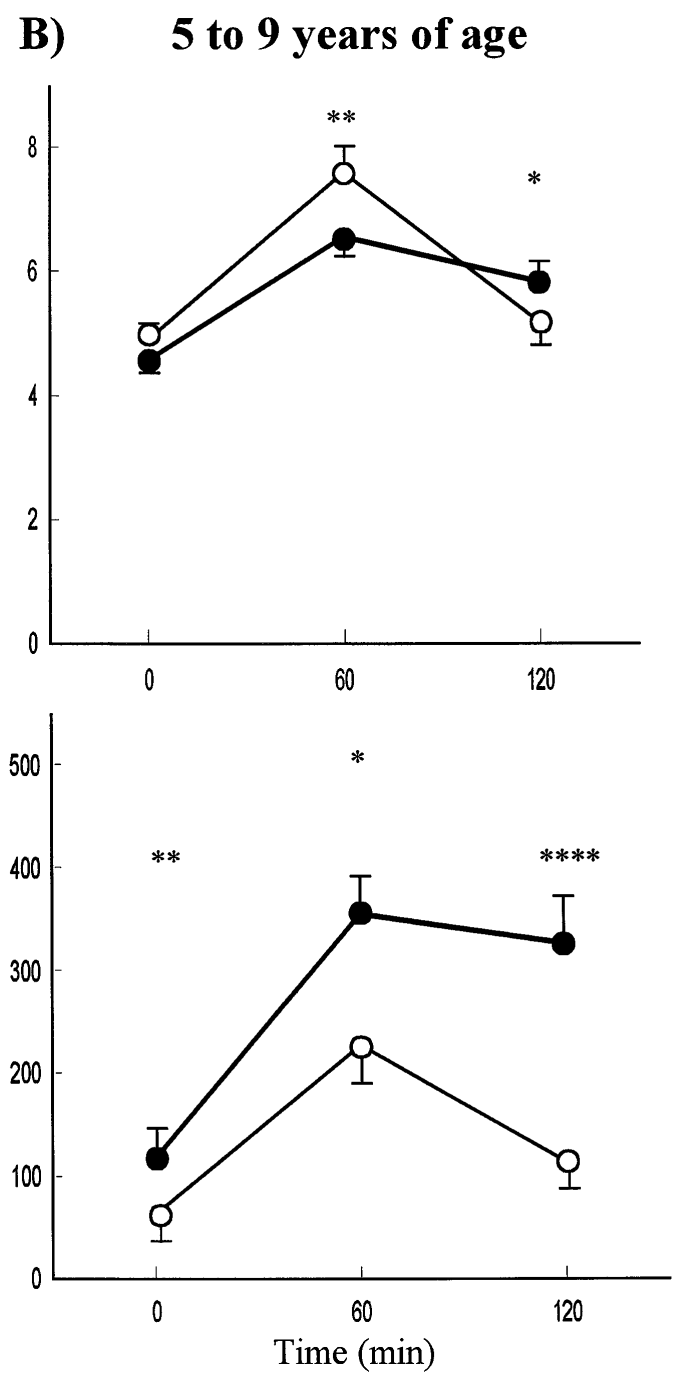
Table 3. Blood glucose and insulin during OGTT in 1-4 and 5-9-year-old infants of gestational diabetic mothers (IGDM) as compared to those of pregestational insulin-dependent diabetic mothers (IDM)

\begin{tabular}{|c|c|c|c|}
\hline $1-4$ years of life & IGDM & IDM & $p$-value ${ }^{a}$ \\
\hline $\mathrm{n}$ & 54 & 106 & \\
\hline Age (years) & $1.58 \pm 0.84$ & $1.61 \pm 0.77$ & $\mathrm{NS}^{\mathrm{b}}$ \\
\hline Body mass index $\left(\mathrm{kg} / \mathrm{m}^{2}\right)$ & $16.2 \pm 0.22$ & $16.0 \pm 0.17$ & NS \\
\hline AUCG $(\mathrm{mmol} / \mathrm{l} \times \mathrm{h})$ & $6.50 \pm 0.28$ & $5.54 \pm 0.13$ & $<0.001$ \\
\hline Fasting plasma insulin $\left(\mathrm{I}^{\prime} ; \mathrm{pmol} / \mathrm{l}\right)$ & $102.9 \pm 10.2$ & $135.8 \pm 11.0$ & NS \\
\hline Maximum insulin value ( $\mathrm{pmol} / \mathrm{l})$ & $208.6 \pm 12.5$ & $251.3 \pm 15.0$ & NS \\
\hline Ratio (AUCI/AUCG) & $25.6 \pm 1.40$ & $33.9 \pm 1.75$ & $<0.02$ \\
\hline \multicolumn{4}{|l|}{ 5-9 years of life } \\
\hline $\mathrm{n}$ & 15 & 23 & \\
\hline Age (years) & $6.42 \pm 0.37$ & $6.28 \pm 1.15$ & $\mathrm{NS}^{\mathrm{b}}$ \\
\hline Body mass index $\left(\mathrm{kg} / \mathrm{m}^{2}\right)$ & $16.2 \pm 0.56$ & $16.9 \pm 0.82$ & NS \\
\hline Fasting blood glucose $\left(\mathrm{BG}^{\prime} ; \mathrm{mmol} / \mathrm{l}\right)$ & $4.90 \pm 0.20^{\mathrm{c}}$ & $4.57 \pm 0.09^{\mathrm{e}}$ & NS \\
\hline Ratio $\left(\mathrm{IO}^{\prime} / \mathrm{BG} 0^{\prime}\right)$ & $13.2 \pm 4.27^{\mathrm{f}}$ & $25.7 \pm 3.22$ & $<0.005$ \\
\hline Ratio (AUCI/AUCG) & $25.1 \pm 5.11$ & $47.1 \pm 5.11^{\mathrm{f}}$ & $<0.002$ \\
\hline
\end{tabular}

Values are expressed as means \pm SEM. AUCG, area under the curve of glucose; AUCI, area under the curve of insulin; ' ysis of covariance, adjusted for age and sex; ${ }^{\mathrm{b}}$ no significant group differences in mean or median age by t-test or U-test,

$120 \min (p<0.001$ and $p<0.005$, respectively), while IGDM displayed a significant decrease of fasting insulin with rising age $(p<0.05)$.

As shown in Table 3 area under the glucose curve (AUCG) was found to be higher in IGDM throughout childhood, while IDM had significantly elevated area under the insulin curve (AUCI) and maximum insulin values at 5-9 years of age. Group differences in fasting insulin concentrations as well as in AUCI were still detectable after adjusting the values for glucose concentration by regression (I0': $p<0.05$; AUCI: $p<0.025$ ). Furthermore, in both age groups IDM displayed significantly higher fasting as well as stimulated insulin/ glucose ratios, compared to IGDM.

Comparing these parameters at 1-4 years to those at 5-9 years of age, IDM developed significantly higher AUCG, maximum insulin values, higher AUCI, and an increase in AUCI/AUCG ratio at an age of 5-9 years as compared to an age of 1-4 years. In contrast, in IGDM increasing AUCG was accompanied by a a significant decrease in fasting insulin/ glucose ratio in later childhood (Table 3). Within the IGDM group, no significant differences between infants of insulin-treated and those of diet-treated mothers could be observed in any parameter.

To estimate possible relations between neonatal parameters and insulin secretion in childhood multiple linear regression analysis was performed, including adjustment for sex and age. Standardized partial regression coefficients revealed independent positive correlations between plasma insulin at birth and respectively; $1-4$ vs $5-9$ years of life: ${ }^{c} p<0.05 ;{ }^{d} p<0.01$; e $p<0.005$; ${ }^{\mathrm{f}} \mathrm{p}<0.001$ (analysis of covariance, adjusted for age and sex)

AUCI $(\mathrm{B}=0.1675 ; \mathrm{p}<0.05 ; \mathrm{n}=87)$ as well as AUCI/AUCG ratio $(B=0.1955 ; p<0.01 ; n=87)$ at 1-9 years of age. Furthermore, insulin/glucose ratio at birth showed an independent positive correlation to AUCI/AUCG ratio at 1-9 years of age $(B=0.2141 ; p<0.005 ; n=87)$.

\section{Discussion}

During childhood, remarkably high frequencies of IGT in both groups of infants of mothers with diabetes during pregnancy were observed. Analysing the same age groups as investigated by Silverman et al. [6], in a European Caucasian population of children of diabetic mothers we were able to confirm their results on rising prevalences of IGT during childhood. In normal populations, IGT in children is a rare event occurring in less than $5 \%[6,19,20]$. Interestingly, our observations displayed no significant differences of prevalence of IGT between IDM and IGDM. Moreover, comparing early and later infancy a marked increase of frequencies of IGT was found in IDM as well as in IGDM, indicating that high frequencies of IGT are not a transient phenomenon in these children. With regard to sex differences in glucose metabolism during childhood [21], it should be emphasized that IGT was observed in similar frequencies in male and female children.

A number of studies was performed in newborns of diabetic mothers. Most authors observed an 
enhanced glucose tolerance in these neonates [22, 23], which is believed to be due to a "conditioning" of the pancreatic beta cells in utero, leading to enhanced secretion of insulin to a glycaemic stimulus. Accordingly, Van Assche et al. [24] described hyperplasia of the beta cells in newborns of diabetic mothers. However, the question remains whether and how this enhanced glucose tolerance in the neonate of a gestational diabetic mother is transformed into IGT in later life. Isles et al. [25] and Molsted-Pedersen [26] reported that enhanced glucose tolerance in newborns of diabetic mothers is resolved within the first days of life, while during glucose infusion over a period of $3 \mathrm{~h}$ King et al. [27] observed a decreased glucose tolerance in these children.

While prevalence of IGT did not differ, significant differences between IDM and IGDM were found in blood glucose and insulin values during OGTT. At all ages, IGDM displayed higher glucose values than IDM while IDM had elevated levels of insulin. These results seem to be in contrast to observations of Persson et al. [14] who observed similar glucose disappearance rates and insulin levels in IDM and IGDM at 5 years of age. However, a tendency towards higher insulin values was also visible in their IDM group. In addition, we found in IDM an increased insulin/ glucose ratio as a measure of insulin resistance [28, 29]. As shown by a similar mean body mass index in the groups (Table 3), these differences between IDM and IGDM could not be explained by different body weights. Furthermore, since insulin secretion as well as the degree of insulin resistance were shown to depend on the stage of sexual maturation [30], it should be stressed that all children of the study were at Tanner stage I [31], indicating that differences in insulin and insulin/glucose ratio could not be the result of different stages of pubertal development. Since all statistics were adjusted for sex and age, a possible influence of these confounding variables could also be excluded.

When younger and older children were compared, in both groups of infants a clear trend towards increased glucose levels in higher age was found. This is in contrast to reports from healthy children [21, 32] who are known to display stable blood glucose values with increasing age. Normally, during a child's development this is combined with a physiological increase in plasma insulin levels until puberty [21, 32, 33 . We could only find in IDM such an increase of insulin levels; however, it was accompanied by an increase of fasting blood glucose and stimulated insulin/glucose ratio. No increase but rather a decrease of insulin values was observed in IGDM, associated with an increase of glucose levels. These findings speak for disturbances of glucose tolerance and insulin secretion patterns in both IDM as well as IGDM. In IDM, a high-response of insulin, together with rising insulin/glucose ratio, might indicate increasing insulin resistance with higher age. This is in accordance with recent observations by Purdy et al. [34] who described increased glucose and insulin values as well as insulin resistance in adolescent offspring of mothers with IDDM. In addition, in IDM an elevation of insulin levels 60 and 120 min after glucose loading as well as an increase of stimulated insulin with rising age could possibly indicate a kind of high and/or delayed insulin response which is frequently observed in patients with NIDDM [35]. In contrast, in IGDM a kind of low insulin response seems to develop during childhood, which is known to occur frequently together with IGT in populations with an increased susceptibility for IDDM, as in siblings of patients with IDDM [36]. Recently, the occurrence of insulin autoantibodies, which are early precursors of IDDM, was reported from infants of gestational diabetic mothers [37]. Our observations match well with insights obtained from animal experiments of Aerts et al. [12] who showed that the offspring of severely diabetic mother rats developed hyperinsulinaemia and insulin resistance in later life, while those offspring born to mothers with only mild diabetes during pregnancy displayed IGT due to reduced insulin output.

However, the question arises why these disturbances developed despite antenatal care in both groups of diabetic pregnant women. As reported by Tallarigo et al. [38] and Kurishita et al. [39], even in non-diabetic, "normoglycaemic" pregnancies, undetected hyperglycaemic episods during pregnancy were shown to influence neonatal outcome. Unfortunately, measurements of $\mathrm{HbA}_{1 \mathrm{c}}$ were not available during the whole study period at the Clinic of Kaulsdorf in the former GDR (East Germany). At birth, both groups of infants were found to be clearly hyperinsulinaemic with insulin values above $210 \mathrm{pmol} / \mathrm{l}$ [40-42]. As shown by the fundamental work of Weiss et al. [43], a more pronounced and prolonged maternal hyperglycaemia in IDM can be presumed to be the main reason of higher fetal and neonatal insulin levels in IDM. Nevertheless, theoretically the possibility of some bias resulting from transplacentally transferred maternal insulin antibodies, which are known to interfere with measurement of neonatal insulin [44], cannot be clearly excluded in each case. Although our study group was considered to be a representative sample of the population of infants of diabetic mothers at our clinic, accidentally a somewhat higher percentage of infants of pregestational diabetic mothers than of those of gestational diabetic mothers entered the study. Possibly, this might reflect a higher compliance to the recommendation of re-examination of their children in mothers suffering from pregestational IDDM.

Finally, analysing correlations between metabolic parameters in childhood and insulin in the newborn we found that stimulated insulin levels and insulin/ 
glucose ratio in childhood were positively correlated to neonatal insulin and insulin/glucose ratio, respectively. Taking into consideration that IDM displayed clearly increased insulin and insulin/glucose ratio at birth and increase of insulin as well as insulin/glucose ratios with rising age, one may speculate that this might be due to a persistent "dysregulation" of insulin secretion acquired during fetal life and combined with early induction of insulin resistance in these infants [45]. This seems to meet with observations in the Pima Indian Study [46, 47] which suggest that obesity and NIDDM are more likely to develop in offspring of women with diabetes during pregnancy than in offspring of non-diabetic or prediabetic women, i.e. women who developed diabetes only after the pregnancy. Moreover, McCance et al. [48] reported IGT and hyperinsulinaemia early in life to be predictable for later development of NIDDM. Nevertheless, our observations should be accomplished by further studies, i.e. by a stratification into a higher number of age groups in a greater sample of children of diabetic mothers.

Our results and others [6, 10-13, 34, 46, 47, 49] are in marked accordance with the concept of a "functional teratogenesis" of increased diabetes susceptibility due to a permanent "malprogramming" of metabolic and/or neuroendocrine systems, induced by the hyperglycaemic and hyperinsulinaemic intrauterine environment to which IDM as well as IGDM are exposed. Therefore, a general glucose intolerance screening during pregnancy and, consequently, special health care for all pregnant diabetic women i.e. long-term as well as gestational diabetic patients - are recommended in order to avoid, or at least reduce, the increased morbidity in their newborns and children by primary prevention [11, 43, 47, 50-53]. Moreover, in view of our observations and those made by other authors, we think that it is necessary to pay special attention to later development of children born to mothers with diabetes during pregnancy.

A cknowledgements. This study was supported in part by research grants from the German Ministry for Research and Technology (BMFT; 01 ZZ 9101), the German Ministry for Education and Research (BMBF; 01 ZZ 9511) and by the German Research Society (DFG; Sfb 174/C11). We thank Mr. J. Wüst for linguistic revision of the manuscript.

This publication contains part of the doctoral thesis of Thomas Harder.

\section{References}

1. Pedersen J (1954) Weight and length at birth of infants of diabetic mothers. Acta Endocrinol 16: 330-342

2. Jorgensen KR, Deckert T, Molsted-Pedersen L, Pedersen J (1966) Insulin, insulin antibody and glucose in plasma of newborn infants of diabetic women. Acta Endocrinol 52: 154-167
3. Heding LG, Persson B, Stangenberg M (1980) B-cell function in newborn infants of diabetic mothers. Diabetologia 19: 427-432

4. Kühl C, Andersen GE, Hertel J, Molsted-Pedersen L (1982) Metabolic events in infants of diabetic mothers during first 24 hours after birth. Acta Paediatr Scand 71: 19-25

5. Toeller M, Gries FA, Kuschak D, Potthoff S (1981) Stoffwechselrisiko bei Kindern von Diabetikerinnen. Arch Gynäkol 232: 548-549

6. Silverman BL, Metzger BE, Cho NH, Loeb CA (1995) Impaired glucose tolerance in adolescent offspring of diabetic mothers. Diabetes Care 18: 611-617

7. Kohlhoff R, Dörner G (1990) Perinatal hyperinsulinism and perinatal obesity as risk factors for hyperinsulinaemia in later life. Exp Clin Endocrinol 96: 105-108

8. Ferrannini E, Haffner SM, Mitchell BD, Stern MP (1991) Hyperinsulinaemia: the key feature of a cardiovascular and metabolic syndrome. Diabetologia 34: 416-422

9. Aerts L, Van Assche FA (1981) Endocrine pancreas in the offspring of rats with experimentally induced diabetes. $\mathbf{J}$ Endocrinol 88: 81-88

10. Bihoreau MT, Ktorza A, Kinebanyan MF, Picon L (1986) Impaired glucose homeostasis in adult rats from hyperglycemic mothers. Diabetes 35: 979-984

11. Dörner G, Plagemann A, Rückert JC et al. (1988) Teratogenetic maternofoetal transmission and prevention of diabetes susceptibility. Exp Clin Endocrinol 91: 247-258

12. Aerts L, Holemans K, Van Assche FA (1990) Maternal diabetes during pregnancy: consequences for the offspring. Diabetes Metab Rev 6: 147-167

13. Plagemann A, Heidrich I, Rohde W, Götz F, Dörner G (1992) Hyperinsulinism during differentiation of the hypothalamus is a diabetogenic and obesity risk factor in rats. Neuroendocrinol Letters 14: 373-378

14. Persson B, Gentz J, Möller E (1984) Follow-up of children of insulin dependent (type I) and gestational diabetic mothers. Acta Paediatr Scand 73: 778-784

15. Fuhrmann K (1988) Gestational diabetes, significance of risk factors and results of a follow-up study 8 years after delivery. In: Weiss PAM, Coustan DR (eds) Gestational diabetes. Springer, Wien, pp 93-98

16. Jährig D, Stiete S, Jonas C (1993) Offspring of diabetic mothers. Problems of morbidity. Diabete Metab 19: 206211

17. National Diabetes Data Group (1979) Classification and diagnosis of diabetes mellitus and other categories of glucose intolerance. Diabetes 28: 1039-1057

18. Minister für Gesundheitswesen der DDR (1983) Deutsches Arzneibuch DAB 8 (D.L.)-DDR. Akademie, Berlin, pp 2101-2103

19. Rosenbloom AL, Wheeler L, Bianchi R, Chin FT, Tiwary CM, Grgic A (1975) Age-adjusted analysis of insulin responses during normal and abnormal glucose tolerance tests in children and adolescents. Diabetes 24: 820-828

20. Josephsberg Z, Vilunski E, Hanukuglu A et al. (1976) Glucose tolerance and insulin responses to an oral glucose load in normal children and adolescents in Israel. Israel J Med Sci 12: 189-193

21. Lautala P, Akerblom HK, Viikari J et al. (1985) Atherosclerosis precursors in Finnish children and adolescents. VII. serum immunoreactive insulin. Acta Paediatr Scand [Suppl 318]: 127-133

22. Gentz J, Lunell NO, Olin P, Persson B, Sterky G (1967) Glucose tolerance in overweight babies and infants of diabetic mothers. Acta Paediatr Scand 56: 228-229 (Letter)

23. Pildes PS, Hart RJ, Warrner R, Cornblath M (1969) Plasma insulin response during oral glucose tolerance tests in 
newborns of normal and gestational diabetic mothers. Pediatrics 44: 76-83

24. Van Assche FA, Gepts W (1971) The cytological composition of the foetal endocrine pancreas in normal and pathological conditions. Diabetologia 7: 434-444

25. Isles TE, Dickson M, Farquhar JW (1968) Glucose tolerance and plasma insulin in newborn infants of normal and diabetic mothers. Pediatr Res 2: 198-208

26. Molsted-Pedersen L (1968) Glucose tolerance in newly born children of diabetic mothers. Acta Paediatr Scand 57: 460-461

27. King KC, Adam PAJ, Clemente GA, Schwartz R (1969) Infants of diabetic mothers: attenuated glucose uptake without hyperinsulinemia during continuous glucose infusion. Pediatrics 44: 381-392

28. Legido A, Sarria A, Bueno M et al. (1987) Relationship of body fat distribution to metabolic complications in obese prepubertal girls. Clin Pediatr 26: 310-315

29. Islam AHMW, Yamashita S, Kotani K et al. (1995) Fasting plasma insulin level is an important risk factor for the development of complications in Japanese obese children results from a cross-sectional and a longitudinal study. Metabolism 44: 478-485

30. Svec F, Nastasi K, Hilton C, Weihang B, Srinivasan SR, Berenson GS (1992) Black-white contrasts in insulin levels during pubertal development. Diabetes 41: 313-317

31. Tanner JM (1962) Growth at adolescence. Blackwell, Oxford

32. Smith CP, Archibald HR, Thomas JM et al. (1988) Basal and stimulated insulin levels rise with advancing puberty. Clin Endocrinol 28: 7-14

33. Allen HF, Jeffers BW, Klingensmith GJ, Chase HP (1993) First-phase insulin release in normal children. J Pediatr 123: 733-738

34. Purdy LP, Silverman BL, Metzger BE (1996) Long-term follow-up of offspring of type I diabetic mothers: status in adolescence. Diabetes 45 [Suppl 2]: 205 (Abstract)

35. Reaven GM, Chen YDI, Hollenbeck CB, Sheu WHH, Ostrega D, Polonsky KS (1993) Plasma insulin, C-peptide, and proinsulin concentrations in obese and nonobese individuals with varying degrees of glucose tolerance. J Clin Endocrinol Metab 76: 44-48

36. Srikanta S, Ganda OP, Rabizadeh A, Soeldner JS, Eisenbarth GS (1985) First-degree relatives of patients with type I diabetes mellitus. NEJM 313: 461-464

37. Ziegler AG, Hillebrand B, Rabl W et al. (1993) On the appearance of islet associated autoimmunity in offspring of diabetic mothers: a prospective study from birth. Diabetologia 36: 402-408

38. Tallarigo L, Giampietro O, Penno G, Miccoli R, Gregori G, Navalesi R (1986) Relation of glucose tolerance to complications of pregnancy in nondiabetic women. NEJM 315: 989-992
39. Kurishita M, Nakashima K, Kozu H (1994) A retrospective study of glucose metabolism in mothers of large babies. Diabetes Care 17: 649-652

40. Hawdon JM, Aynsley-Green A, Alberti KGMM, Ward Platt MP (1993) The role of pancreatic insulin secretion in neonatal glucoregulation. I. Healthy term and preterm infants. Arch Dis Childh 68: 274-279

41. Francois R, Picaud JJ, Ruitton-Ugliengo A, David L, Cartal MJ, Bauer D (1974) The newborn of diabetic mothers. Biol Neonate 24: 1-31

42. Falorni A, Fracassini F, Massi-Benedetti F, Amici A (1972) Glucose metabolism, plasma insulin, and growth hormone secretion in newborn infants with erythroblastosis fetalis compared with normal newborns and those born to diabetic mothers. Pediatrics 49: 682-693

43. Weiss PAM, Hofmann H, Pürstner P, Winter R, Lichtenegger W (1984) Fetal insulin balance: gestational diabetes and postpartal screening. Obstet Gynecol 64: 65-68

44. Chertow BS, Baranetsky NG, Sivitz WI, Swain PA, Grey J, Charles D (1988) The effect of human insulin on antibody formation in pregnant diabetics and their newborns. Obstet Gynecol 72: 724-728

45. Dörner G, Plagemann A (1994) Perinatal hyperinsulinism as a possible predisposing factor for diabetes mellitus, obesity, and enhanced cardiovascular risk in later life. Horm Metab Res 26: 213-221

46. Pettitt DJ, Baird HR, Aleck KA, Bennett PH, Knowler WC (1983) Excessive obesity in offspring of Pima Indian women with diabetes during pregnancy. NEJM 308: 242245

47. Pettitt DJ, Aleck KA, Baird HR, Carraher MJ, Bennett PH, Knowler WC (1988) Congenital susceptibility to NIDDM. Role of intrauterine environment. Diabetes 37: 622628

48. McCance DR, Pettitt DJ, Hanson RL, Jacobsson LTH, Bennett PH, Knowler WC (1994) Glucose, insulin concentrations and obesity in childhood and adolescence as predictors of NIDDM. Diabetologia 37: 617-623

49. Silverman BL, Rizzo T, Green OC et al. (1991) Long-term prospective evaluation of offspring of diabetic mothers. Diabetes 40 [Suppl 2]: 121-125

50. Dörner G, Steindel E, Kohlhoff R, Reiher H, Anders B, Verlohren HJ (1985) Further evidence for a preventive therapy of insulin-dependent diabetes mellitus in the offspring by avoiding maternal hyperglycaemia during pregnancy. Exp Clin Endocrinol 86: 129-140

51. Dörner G (1975) Perinatal hormone levels and brain organization. In: Stumpf WE, Grant LD (eds) Anatomical neuroendocrinology. Karger, Basel, pp 245-252

52. Freinkel N (1980) Of pregnancy and progeny. Diabetes 29: 1023-1035

53. Deutsche Diabetes Gesellschaft (1996) Empfehlungen für die Betreuung der Neugeborenen diabetischer Mütter. Diabetes und Stoffwechsel 5: 37-38 